\title{
Science to inform climate policy targets
}

\author{
Ambitious temperature targets are intended to be catalysts of political and practical action on climate \\ change. They also pose many applied research questions to science.
}

Perhaps one of the more surprising outcomes of the December 2015 Paris Agreement was the inclusion of the politically ambitious intention to keep the increase in average global temperature well below $2{ }^{\circ} \mathrm{C}$ above pre-industrial levels, and to strive to limit the increase to $1.5^{\circ} \mathrm{C}$ on the basis that "this would significantly reduce risks and the impacts of climate change". In support of this ambition, and following an invitation from the UNFCCC, the IPCC agreed to undertake a special report on the potential costs and benefits of a global average temperature rise of $1.5^{\circ} \mathrm{C}$ rather than $2{ }^{\circ} \mathrm{C}$ above pre-industrial levels. The report will be published in 2018, and loosely focus on the impacts and related global greenhouse gas emission pathways. But the details of the report remain to be established and the most appropriate focus for this work is somewhat controversial.

The science-policy interactions at play here are complex; with science having played only a partial (yet significant) role in informing the formulation of the policy objectives that are now feeding back into scientific research agendas. The IPCC Special Report will only assess published research, so its focus can only indirectly steer research communities' efforts. Nevertheless the IPCC's choices will probably influence, and inevitably be influenced by, the choices of individual research communities, many of whom will directly contribute.

In an effort to provide a resource that brings together diverse viewpoints about how researchers could and/or should respond to this policy challenge Nature Climate Change, Nature Geoscience and Nature present a joint web Collection (http:// www.nature.com/1.5degclimatetarget). In the first instance, this joint Collection will draw together opinion and comment pieces that discuss the potential ways ahead for various research areas following Paris, over time the Collection page will also act as a repository for important new research that addresses questions related to the merits and uncertainties associated with striving to achieve these temperature targets.

Some commentators suggest that the $1.5^{\circ} \mathrm{C}$ ambition (notably, it is not a target) was a bargaining chip given by developed nations in exchange for excluding any mention of liability in the Paris Agreement (for example see Petherick's News Feature, p741). Depending on your disposition, this could make the revised climate ambitions established in Paris seem wishful, or worse, wilfully misleading. Or it could be viewed as astute bargaining by the developing nations, along with many interpretations in between. Despite (or perhaps because) such policy objectives arise out of a globally negotiated deliberative process - much of the time far removed from scientific data and reasoning - Simon Lewis (Nature http://doi.org/bk43; 2016) has argued that this agreement has in effect finally defined what society considers dangerous in terms of climate change. This may well be an important step in itself but, as anybody who has made a New Year's resolution knows, deciding on a target and achieving it are two very different things.

In discussing the implications of the Paris Agreement for policy relevant research (Nature Clim. Change 6, 222-224; 2016) Mike Hulme questions the extent that researchers and funders should "bend their research agendas, programmes and projects towards the types of short-term policy-oriented question that emerge from negotiations such as those at Paris" and concludes that scientists should "be cautious and not naively be drawn into undertaking new cycles of studies in the expectation that they will make a difference to the world of politics". Some caution certainly seems warranted given that the stakes are high, but some researchers are taking what might be characterized as a more trusting view.

One starting point for understanding and communicating the costs and benefits of climate policies is through a mapping exercise that systematically explores the consequences of various policy choices. This exercise was undertaken to help structure the synthesis report of the IPCC's Fifth Assessment Report, and Stephane Hallegatte and co-authors (Nature Clim. Change $6,663-668$; 2016) use it to form the basis of a discussion of the strengths and limitations of a mapping approach and its utility for decision-makers. Their revised diagram is a useful way to visualize and contextualize the particular challenges ahead.

Rogelj \& Knutti (Nature Geosci. 9, 187-189; 2016) take a fairly straightforward cue from Paris to discuss some key research areas that will need to be bolstered to inform a $1.5^{\circ} \mathrm{C}$ target and tease out its differences from a $2{ }^{\circ} \mathrm{C}$ world. These include issues connected with temperature overshoot and subsequent recovery, negative emissions, non- $\mathrm{CO}_{2}$ greenhouse gas contributions and differential impacts at specified warming levels.

Taking a similar frame of reference but focusing particularly on the analysis needed to understand the impacts of a $1.5^{\circ} \mathrm{C}$ warmer world, Daniel Mitchell and co-authors (p735) argue that the academic community could make rapid progress in quantifying the impacts of limiting global warming to $1.5^{\circ} \mathrm{C}$, and suggest some refocusing of research priorities to do so. Furthermore, they argue that if research is not undertaken as a matter of urgency, a 2018 special report may present the negative economic constraints of achieving $1.5^{\circ} \mathrm{C}$ but with insufficient evidence to distinguish the potential reduction in impacts.

By now it is clear that global average temperature is a property we are able to influence, but not necessarily control, and there remain important questions about how actionable a temperature target might be even in principal. Glen Peters (Nature Clim. Change 6, 646-649; 2016) argues that the uncertainties around the relationship of emissions to temperature change, prospects for carbon removal/negative emissions, and carbon pricing, are sufficiently great to make measuring whether we are on target for $1.5^{\circ} \mathrm{C}$ or $2{ }^{\circ} \mathrm{C}$ intractable in practice. He suggests that efforts should focus on reducing the uncertainties around these elements, rather than a $1.5^{\circ} \mathrm{C}$ pathway itself. In a somewhat similar vein Oliver Geden (Nature Geosci. 9, 340-342; 2016) contends that we should focus on a target with the best potential to effectively guide policy; netzero emissions. He goes on to suggest that a zero emissions target would have the benefit of providing a clear direction of travel where target attainability would be a question of sooner/later rather than either/or.

This is only a brief taster of the viewpoints currently brought together in this Collection. We hope that they will provide a useful resource for researchers deciding how best to lend their weight to research efforts post Paris. 